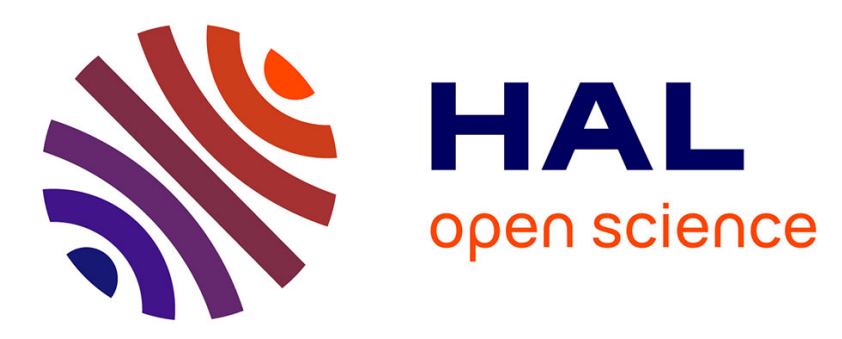

\title{
Direct Synthesis of Thiocarbamoyl Fluorides and Trifluoromethylamines Through Fluorinative Desulfurization
}

Killian Onida, Laurent Vanoye, Anis Tlili

\section{- To cite this version:}

Killian Onida, Laurent Vanoye, Anis Tlili. Direct Synthesis of Thiocarbamoyl Fluorides and Trifluoromethylamines Through Fluorinative Desulfurization. European Journal of Organic Chemistry, 2019, 2019 (35), pp.6106-6109. 10.1002/ejoc.201901113 . hal-03008845

\section{HAL Id: hal-03008845 \\ https://hal.science/hal-03008845}

Submitted on 21 Dec 2020

HAL is a multi-disciplinary open access archive for the deposit and dissemination of scientific research documents, whether they are published or not. The documents may come from teaching and research institutions in France or abroad, or from public or private research centers.
L'archive ouverte pluridisciplinaire HAL, est destinée au dépôt et à la diffusion de documents scientifiques de niveau recherche, publiés ou non, émanant des établissements d'enseignement et de recherche français ou étrangers, des laboratoires publics ou privés. 


\title{
Direct Synthesis of Thiocarbamoyl Fluorides and Trifluoromethylamines through Fluorinative Desulfurization
}

\author{
Killian Onida, ${ }^{[a]}$ Laurent Vanoye, ${ }^{[b]}$ and Anis Tlili*[a]
}

\begin{abstract}
Herein, a straightforward synthesis of thiocarbamoyl fluorides is reported starting from amines and carbon disulfide. The key to success is the fluorinative desulfurization of carbon disulfide with (diethylamino)sulfurtrifluroide (DAST). The title compounds were obtained in moderate to very good isolated yields. Furthermore, we demonstrated also that thiocarbamoyl fluoride can be converted to their trifluoromethyl amine analogues through simple treatment with silver fluoride.
\end{abstract}

\section{Introduction}

Fluorinated compounds have gained widespread interest in the last years. ${ }^{[1]}$ The physicochemical properties gained through the incorporation of fluorine or fluorinating groups is the driving force for this perpetual interest. To be said, high lipophilicity as well as high oxidation resistance are among the most desired properties. ${ }^{[2]}$ On the other hand the presence of nitrogen moieties is even more frequent in bioactive compounds. ${ }^{[3]}$ Thus, the association of fluorine and nitrogen represent a highly covetable synthetic target.

In this context, thiocarbamoyl fluorides constitute an attractive core structure in organic synthesis. ${ }^{[4]}$ The direct synthesis of these compounds has been revisited recently. The group of Schoenebeck ${ }^{[5]}$ demonstrated that amines react with $\left(\mathrm{Me}_{4}\right) \mathrm{NSCF}_{3}$, a nucleophilic trifluoromethylthiolating reagent, furnishing thiocarbamoyl fluorides within 10 min at room temperature (Scheme 1, I). Herein the stability of the trifluoromethylating reagent is the key to success. Indeed, it has been shown that the in-situ generation of thiocarbonyl fluoride $\left(\mathrm{F}_{2} \mathrm{C}=\mathrm{S}\right)$ allows the formation of the desired thiocarbamoyl fluoride. Afterwards, the group of Lin and $\mathrm{Xiao}^{[6]}$ demonstrated that thiocarbonyl fluoride can be obtained in-situ by reacting difluorocarbene generated from $\mathrm{Ph}_{3} \mathrm{P}^{+} \mathrm{CF}_{2} \mathrm{CO}_{2^{-}}$(PDFA) and $\mathrm{S}_{8}$ (Scheme 1, II). In both methodologies (I \& II), the authors used thiocarbamoyl intermediates for the synthesis of trifluromethylamines. ${ }^{[7]}$ Recently, the group of Jiang ${ }^{[8]}$ demonstrated that thiocarbonyl fluoride can be formed by two distinct ways. On the one hand, the association of the Ruppert-Prakash reagent with elementary sulfur and potassium fluoride allows the in-situ formation of thiocarbonyl fluoride. The latter can also be generated starting from $\mathrm{AgSCF}_{3}$ in conjunction with potassium bromide (Scheme 1, III). More recently, the group of Jiang and Yi demonstrated that the Langlois reagent could also be used in conjunction with triphenylphosphine to form thiocarbamoyl fluorides (Scheme 1, IV). ${ }^{[9]}$ In this context, we thought that the straightforward synthesis of thiocarbamoyl fluoride through fluorinative desulfurization would constitute an attractive option for the access thiocarbamoyl fluorides.
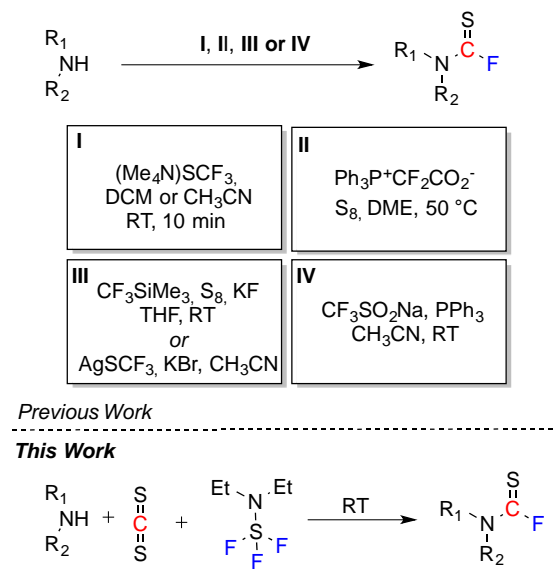

Scheme 1. State of the art: Synthesis of thiocarbamoyl fluoride using amines

\section{Results and Discusion}

We recently initiated a new research program aiming at activating small molecules for the fluorination of organic compounds and presumed that investigating an unprecedented fluorinative desulfurization would be the key to success for our methodology.$^{[10]}$ To do so, we selected amine 1a as model substrate in conjunction with 1 equivalent of $\mathrm{CS}_{2}$ and an excess of (diethyamino)sulphur 
trifluoride (DAST, 3 equiv.). We were pleased to observe the formation of the desired product in $45 \%$ yield (table 1, entry 1 ) when the reaction was performed in toluene in the presence of an external base ( 0.5 equiv. of DIPEA). Next, we investigated the impact of the solvent on the reaction outcome. The use of DMSO furnished the desired product in very low yield of $9 \%$ (table 1, entry 2). When DMF and THF were used the desired product was observed in similar yield as before with toluene (Table 1 , entries 3 \& 4). Moving on to $\mathrm{MeCN}$, a better yield of $51 \%$ (entry 5 ) was obtained. It turns out that DCM is the most efficient solvent under our reaction conditions since $71 \%$ of the desired product was obtained. It should be mentioned that lower reaction outcome was observed when the reaction was performed with 1 equivalent of the base. Also, the presence of DIPEA is fundamental to the formation of the desired product since only traces of the product were obtained in the absence of the base (table 1 , entry 7 ).

Afterwards, we decided to screen several bases. Good reactivity was observed when $\mathrm{NEt}_{3}$ and DBU were used as 62 and $57 \%$ of the desired product was formed, respectively. Only low yield was obtained when pyridine derivatives, DMAP and 2,6-Lutidine were employed (Table 1, entries 10 \& 11). Finally, the yield dropped to $60 \%$ when the quantity of DAST was decreased from 3 to 2 equivalents (Table 1, entry 12).

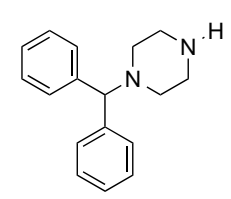

$1 \mathrm{a}$

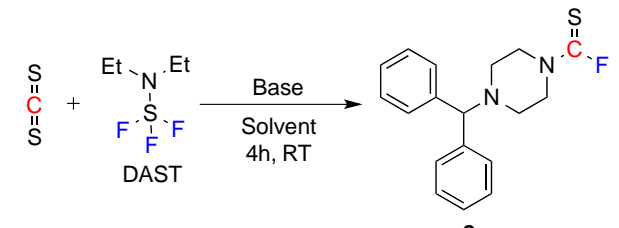

$2 a$

\begin{tabular}{cccc}
\hline \hline Entry & Solvent & Base & Yield $(\%)^{\mathrm{b}}$ \\
\hline 1 & PhMe & DIPEA & 45 \\
2 & DMSO & DIPEA & 9 \\
3 & DMF & DIPEA & 42 \\
4 & THF & DIPEA & 45 \\
5 & ACN & DIPEA & 51 \\
6 & DCM & DIPEA & $71,50^{\circ}$ \\
7 & DCM & - & 2 \\
8 & DCM & Et ${ }_{3} N$ & 62 \\
9 & DCM & DBU & 57 \\
10 & DCM & DMAP & 30 \\
11 & DCM & 2,6-Lutidine & 6 \\
12 & DCM & DIPEA & $60^{d}$
\end{tabular}

[a] Reactions were performed with 1a (1 mmol, 1 equiv.), DAST (3 mmol, 3 equiv.), $\mathrm{CS}_{2}$ ( 1 mmol, 1 equiv.), base (0.5 mmol, 0.5 equiv.) and solvent $(4 \mathrm{~mL})$. The reaction mixture was stirred at $\mathrm{rt}$ for 4 hours. [b] Determined by ${ }^{19} \mathrm{~F}$ NMR spectroscopy with PhOCF 3 as an internal standard. [c] Reaction performed with 1 equiv. of DIPEA. [d] Reaction performed with 2 equiv. of DAST. DIPEA= N,N-Diisopropylethylamine. DMAP = 4Dimethylaminopyridine. 
Next, we investigated the use of different deoxyfluorinating reagents. It turns out that the product was formed only in the presence of DAST and no traces were observed with XtalFluor- $\mathrm{E}^{\circledR}$, XtalFluor-M ${ }^{\circledR[11]}$ neither with Fluolead ${ }^{\mathrm{TM}[12]}$ (Table 2

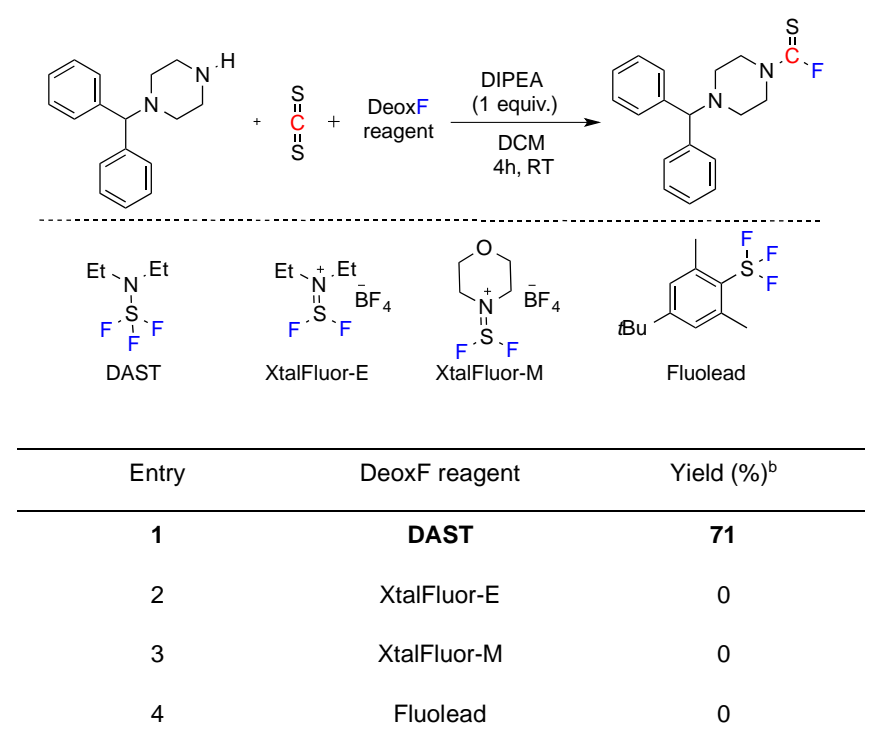

[a] Reactions were performed with 1a (1 mmol, 1 equiv.), DAST (3 mmol, 3 equiv.), $\mathrm{CS}_{2}$ ( $1 \mathrm{mmol}, 1$ equiv.), base $(0.5 \mathrm{mmol}, 0.5$ equiv.) and solvent $(4 \mathrm{~mL})$. The reaction mixture was stirred at it for 4 hours. [b] Determined by ${ }^{19} \mathrm{~F}$ NMR spectroscopy with $\mathrm{PhOCF}_{3}$ as an internal standard.

With the best conditions in hand we turned our attention to study the reaction scope (Scheme 2). Overall, the desired product was obtained in synthetically useful to excellent yields with excellent selectivities. The reaction conditions tolerate the presence of unsaturated compounds. For example, thiocarbamoyl fluoride $2 \mathrm{c}$ was obtained in moderate yield of $48 \%$. The presence of chlorine substituent is also tolerated under our reaction conditions and the corresponding product was obtained in a moderate yield of $51 \%$ (product $\mathbf{2 e}$, Scheme 2).

Tetrahydropyridine 1i was also converted successfully into the corresponding thiocarbamoyl fluoride in good yield of $69 \%$. Interestingly benzylic amines were tolerated under the developed conditions furnishing the desired products in excellent yield (up to $90 \%$ ), products $\mathbf{2 k}$ and $\mathbf{2 l}$. Finally, we were able to to observe that bioactive amine compounds were also tolerated under these conditions. Indeed Notriptyline, Desipramine as well as Maprotiline derivatives were converted to their corresponding thiocarbamoyl derivatives in very good to excellent yield (up to $99 \%$, products $2 m, 2 n \& 20$ ). 


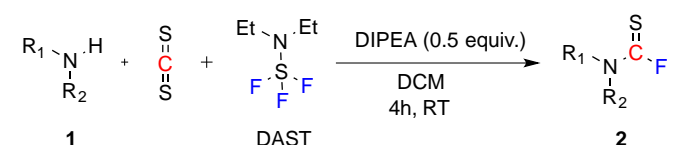<smiles>O=C(F)N1CCN(C(=S)N2CCN(Cc3ccccc3)CC2)CC1</smiles><smiles>FC(=S)N1CCN(C(=S)N2CCN(c3ccc(Cl)cc3)CC2)CC1</smiles>

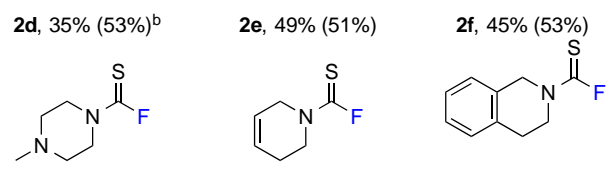
2g, $(78 \%)^{\mathrm{c}}$<smiles>COc1cc2c(cc1OC)CN(C(F)=S)CC2</smiles><smiles>CN(Cc1ccccc1)C(F)=S</smiles><smiles>CCN(Cc1ccccc1)C(F)=S</smiles>

2j, $66(83 \%)^{\mathrm{b}}$

2k, $82(90 \%)^{\mathrm{b}}$

2l, $76(83 \%)$<smiles>CN(CCC=C1c2ccccc2CCc2ccccc21)C(F)=S</smiles>

$2 \mathrm{~m}, 64 \%(94 \%)^{\mathrm{b}}$

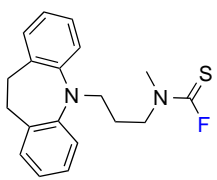

2n, $53 \%(70 \%)^{b}$

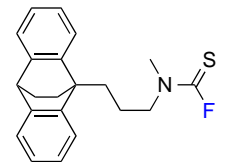

2o, $26(76 \%)^{\mathrm{b}}$

Scheme 2. Reaction scope, Thiocarbamoyl Fluoride: [a] Reactions were performed with $1 \mathrm{a}$ ( $1 \mathrm{mmol}, 1$ equiv.), DAST ( $3 \mathrm{mmol}, 3$ equiv.), CS2 ( $1 \mathrm{mmol}$, 1 equiv.), base $(0.5 \mathrm{mmol}, 0.5$ equiv.) and solvent $(4 \mathrm{~mL})$. Yields shown are those of isolated products; yields determined by 19F NMR spectroscopy with PhOCF3 as internal standard are shown in parentheses. [c] Starting amine derivative was used as $\mathrm{HCl}$ salt in the presence of 1.5 equiv. of DIPEA. [c] 1a ( $0.5 \mathrm{mmol}, 1$ equiv.), DAST ( $1 \mathrm{mmol}, 2$ equiv.), CS2 ( $1 \mathrm{mmol}, 1$ equiv.), base ( $0.5 \mathrm{mmol}, 0.5$ equiv.) and solvent $(4 \mathrm{~mL})$.

As demonstrated earlier by the group of Schoenebeck, we confirmed that trifluoromethyl amines can be obtained starting with thiocarbamoyl fluorides through sample reaction with silver fluoride in $\mathrm{CH}_{3} \mathrm{CN}$ at $50{ }^{\circ} \mathrm{C}$ for $4 \mathrm{~h}$ (Scheme 3). The desired trifluromethylamine derivatives are obtained in general with excellent isolated yields through sample filtration of the crude. 

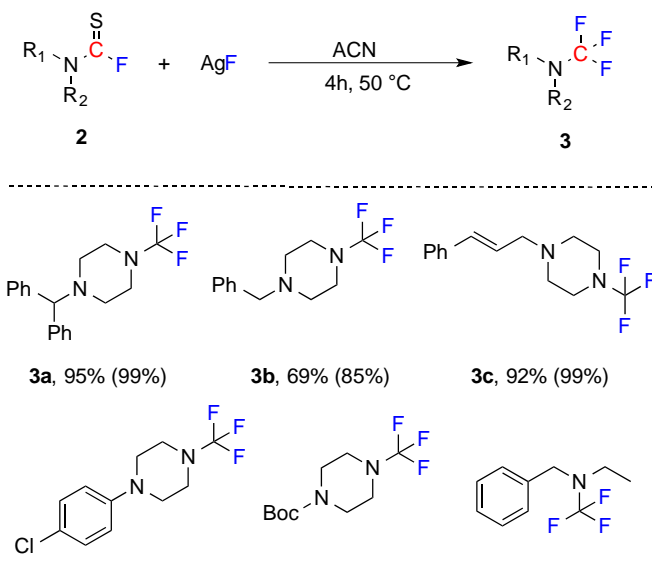
3e, $90 \%(95 \%)$
3f, $89 \%(98 \%)$
31, $(81 \%)$

Scheme 3. Reaction scope, Trifluoromethylation of amines: [a] Reactions were performed with 1a ( $0.2 \mathrm{mmol}, 1$ equiv.), $\mathrm{AgF}$ ( $0.6 \mathrm{mmol}, 3$ equiv.) and $\mathrm{MeCN}(2$ $\mathrm{mL}$ ). Yields shown are those of isolated products; yields determined by ${ }^{19} \mathrm{~F} N \mathrm{NR}$ spectroscopy with $\mathrm{PhOCF}_{3}$ as internal standard are shown in parentheses.
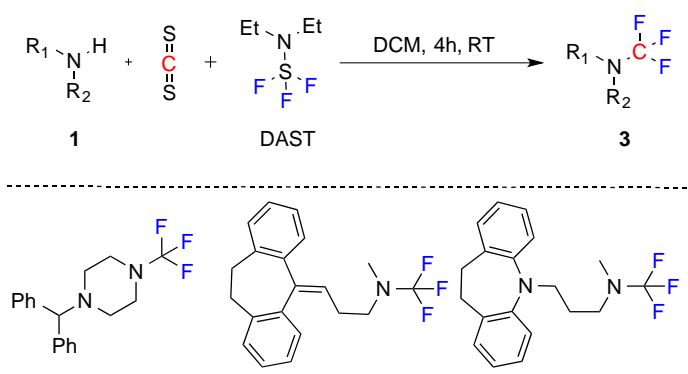

3a, $(99 \%) \quad 3 m,(99 \%)^{\text {b }} \quad 3 n,(99 \%)^{\text {b }}$

Scheme 4. Reaction scope, direct trifluoromethylation of amines : [a] Reactions were performed with $1 \mathrm{a}$ ( $1 \mathrm{mmol}, 1$ equiv.), $\mathrm{CS}_{2}$ ( $0.5 \mathrm{mmol}, 1$ equiv.), DAST (1.5 mmol, 3 equiv.), and DCM ( $2 \mathrm{~mL})$.; yields determined by ${ }^{19} \mathrm{~F}$ NMR spectroscopy with $\mathrm{PhOCF}_{3}$ as internal standard are shown in parentheses. [b] Starting amine derivative was used as $\mathrm{HCl}$ salt in the presence of 1 equiv. of $\mathrm{NEt}_{3}$.

It should be mentioned that the direct access to trifluoromethylated amines could be established in the absence of the base. Indeed, excellent yield (up to $99 \%$, 3a, 3n \& 3o, scheme 4) of the corresponding trifluoromethyl amines was obtained starting from amines (Scheme 4). Unfortunately, we observed the degradation of these compounds upon purification on column

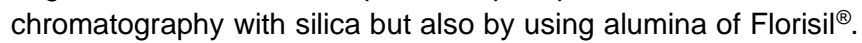
The main by product obtained is the corresponding carbamoyl fluoride.

Regarding the mechanism, we assume that amines reacts with carbon disulphide to form intermediate $\mathbf{A}$. this later could be transformed to compounds B in the presence of DAST and the starting amine is regenerated in the presence of the base (DIPEA). Finally, the desired thiocarbamoyl fluoride is obtained

through inter/intra molecular fluorine attack and diethylsulfuramidothious fluoride C (Scheme 5). 


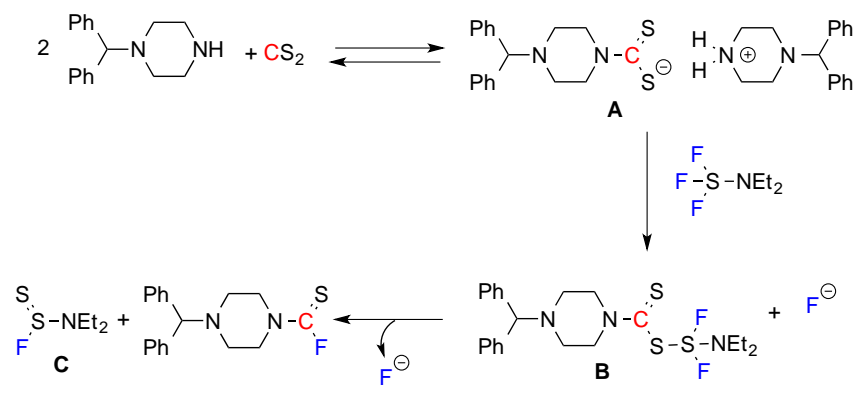

Scheme 5. Proposed mechanism

\section{Conclusion}

In conclusion we demonstrated herein that thiocarbamoyl fluoride could be easily obtained starting with amines through unprecedented fluorinative desulfurization of carbon disulfide with DAST. The desired products are obtained in moderate to very good isolated yields. The title product can easily be converted to trifluoromethyl amines.

\section{Experimental Section}

Synthesis of Piperidine-1- carbothioyl fluoride: To a flame dried Schlenk flask were added the amine ( $1.0 \mathrm{mmol}, 1.0$ equiv.), if a solid. The flask was evacuated and backfilled with $\mathrm{N}_{2} 3$ times, then dry DCM (4 mL) was added by syringe. Then, the amine ( $1.0 \mathrm{mmol}, 1.0$ equiv), if a liquid, and the $\mathrm{CS}_{2}(1.0 \mathrm{mmol}, 1.0$ equiv.) were successively added to the Schlenk flask equipped with a balloon of $\mathrm{N}_{2}$. Then DAST is added $(3.0 \mathrm{mmol}, 3$ equiv.) dropwise the reaction has been observed to be exothermic. The reaction mixture was stirred at $25^{\circ} \mathrm{C}$ for $4 \mathrm{~h}$ (conversion is checked by ${ }^{19} \mathrm{~F}$ NMR with $\mathrm{PhOCF}_{3}$ as internal standard). The crude reaction mixture was diluted with $\mathrm{DCM}(8 \mathrm{~mL})$ and water $(4 \mathrm{~mL})$. Following phase separation, the aqueous layer was extracted with DCM $(3 \times 5 \mathrm{~mL})$. The resulting organic layer was washed with brine $(1 \times 2 \mathrm{~mL})$, The organic layer was dried over anhydrous $\mathrm{MgSO} 4$ and evaporated under reduced pressure (rotary evaporator). The residue was purified by column chromatography to give the desired thiocarbamoyl fluoride product.

\section{Acknowledgements}

This work was supported by the CNRS, COLUMN, ICL (Institut de Chimie de Lyon).

Keywords: Thiocarbamoyl Fluorides • Trifluoromethylamine • DAST • Fluorine - Amines

[1] a) in Fluorine in Life Sciences: Pharmaceuticals, Medicinal Diagnostics, and Agrochemicals. (Eds.: G. Haufe, F. Leroux), Elsevier Science, London, United Kingdom, 2018, pp. 459-518.e) P. Kirsch in Modern Fluoroorganic Chemistry, Wiley-VCH, Wheineim, 2013; f) D. O'Hagan, Chem. Soc. Rev. 2008, 37, 308-319.

[2] a) A. Leo, C. Hansch, D. Elkins, Chem. Rev. 1971, 71, 525-616; b) L. Bruno, W. Zhong, C. Guillaume, P. Vincent, F. C. Q., W. Neil, W. W. Alex, Angew. Chem. Int. Ed. 2016, 55, 674-678; c) W. K. Hagmann, J. Med. Chem. 2008, 51, 4359-4369.

[3]

E. Vitaku, D. T. Smith, J. T. Njardarson, J. Med. Chem. 2014, 57, 10257-10274 
[4] a) F. Leroux, P. Jeschke, M. Schlosser, Chem. Rev. 2005, 105, 827856; b) N. Azizi, F. Aryanasab, M. R. Saidi, Org. Lett. 2006, 8, 5275-5277; c) W. Walter, K.-D. Bode, Angew. Chem. Int. Ed. 1967, 6, 281-293.

[5] a) T. Scattolin, K. Deckers, F. Schoenebeck, Angew. Chem. Int. Ed. 2017, 56, 221-224; b) T. Scattolin, M. Pu, F. Schoenebeck, Chem. Eur. J. 2018, 24, 567-571; c) T. Scattolin, K. Deckers, F. Schoenebeck, Org. Lett. 2017, 19, 5740-5743.

[6] J. Yu, J.-H. Lin, J.-C. Xiao, Angew. Chem. Int. Ed. 2017, 56, 1666916673.

[7] T. Milcent, B. Crousse, Comptes Rendus Chimie 2018, 21, 771-781.

[8] L. Zhen, H. Fan, X. Wang and L. Jiang, Org. Lett. 2019, 21, 21062110 .

[9] S. Liang, J. Wei, L. Jiang, J. Liu, Y. Mumtaz, W. Yi, Chem. Commun. 2019. $10.1039 / C 9 C C 03282 G$

[10] K. Onida, A. Tlili, Angew. Chem. Int. Ed. 2019, 58, 10.1002/anie.201907354

[11] a) F. Beaulieu, L.-P. Beauregard, G. Courchesne, M. Couturier, F. LaFlamme, A. L'Heureux, Org. Lett. 2009, 11, 5050-5053; b) A. L'Heureux, F. Beaulieu, C. Bennett, D. R. Bill, S. Clayton, F. LaFlamme, M. Mirmehrabi, S. Tadayon, D. Tovell, M. Couturier, J. Org. Chem. 2010, 75, 3401-3411.

[12] T. Umemoto, R. P. Singh, Y. Xu, N. Saito, J. Am. Chem. Soc. 2010, 132, 18199-18205. 